\title{
Forelimb musculoskeletal-tendinous growth in frogs
}

\author{
Monica C Solíz ${ }^{\text {Corresp., Equal first author, } 1 \text {, María Jose Tulli }}{ }^{\text {Corresp., Equal first author, 2, } 3 \text {, Virginia Abdala }}{ }^{4}$ \\ ${ }^{1}$ Cátedra Vertebrados, Facultad de Ciencias Naturales, Universidad Nacional de Salta, Salta, Argentina \\ 2 UEL-CONICET, Instituto de Herpetología- Fundación Miguel Lillo, Tucumán, Argentina \\ 3 Cátedra de Biología Animal, Facultad de Ciencias Naturales, Universidad Nacional de Tucumán, Tucuman, Argentina \\ 4 Instituto de Biodiversidad Neotropical (IBN), Cátedra de Biología General, Facultad de Ciencias Naturales, UNT., UNT-CONICET., Tucumán, Argentina \\ Corresponding Authors: Monica C Solíz, María Jose Tulli \\ Email address: monica.c.soliz@gmail.com, majotulli@gmail.com
}

The tendons unite and transmit the strength of the muscles to the bones, allowing movement dexterity, the distribution of the strength of the limbs to the digits, and an improved muscle performance for a wide range of locomotor activities. Tissue differentiation and maturation of the structures involved in locomotion are completed during the juvenile stage; however, few studies have investigated the ontogenetic variation of the musculoskeletal-tendinous system. We ask whether all those integrated tissues and limb structures growth synchronically between them and along with body length. We examined the ontogenetic variation in selected muscles, tendons and bones of the forelimbs in seventy-seven specimens belonging to seven anuran species of different clades and of three age categories, and investigate the relative growth of the forelimb musculoskeletal-tendinous structures throughout ontogeny. Ten muscles and nine tendons and their respective large bones (humerus and radioulna) were removed intact, and their length was measured and analyzed through a multivariate approach of allometry. We obtained an allometry coefficient, which indicates how the coefficient departures from isometry as well as allometric trends. Our data suggest that along with the postmetamorphic ontogeny, muscles tend to elongate proportionally to bone length, with a positive allometric trend. On the contrary, tendons show a negative allometric growth trend. Only two species show different patterns: Rhinella granulosa and Physalaemus biligonigerus, with an isometric and positive growth of muscles and bones, and most tendons being isometric. 


\section{Forelimb musculoskeletal-tendinous growth in frogs}

2 Mónica Carina Soliz ${ }^{1 *}$, María José Tulli2*, Abdala Virginia ${ }^{3}$

$3{ }^{1}$ Universidad Nacional de Salta, Facultad de Ciencias Naturales, Cátedra Vertebrados, Salta, 4 Argentina

$5{ }^{2}$ UEL-CONICET- Instituto de Herpetología- Fundación Miguel Lillo. Cátedra de Biología

6 Animal, Facultad de Ciencias Naturales, UNT. Tucumán, Argentina ORCID: 0000-0003-4763$7 \quad 6973$

$9{ }^{3}$ Instituto de Biodiversidad Neotropical (IBN), UNT-CONICET. Cátedra de Biología General, 10 Facultad de Ciencias Naturales, UNT. Tucumán, Argentina ORCID: 0000-0002-4615-5011

Corresponding Author:

${ }^{1}$ Mónica Carina Soliz Universidad Nacional de Salta (UNSa), Facultad de Ciencias Naturales, 16 Cátedra Vertebrados, Salta, Argentina (4200).monica.c.soliz@gmail.com

${ }^{2}$ María José Tulli UEL-CONICET- Instituto de Herpetología- Fundación Miguel Lillo. Cátedra de Biología Animal, Facultad de Ciencias Naturales, UNT. San Miguel de Tucumán, Tucumán,

19 Argentina (4000). majotulli@gmail.com.

\section{Abstract}

The tendons unite and transmit the strength of the muscles to the bones, allowing movement dexterity, the distribution of the strength of the limbs to the digits, and an improved muscle 
31 performance for a wide range of locomotor activities. Tissue differentiation and maturation of

32 the structures involved in locomotion are completed during the juvenile stage; however, few

33 studies have investigated the ontogenetic variation of the musculoskeletal-tendinous system. We

34 ask whether all those integrated tissues and limb structures growth synchronically between them

35 and along with body length. We examined the ontogenetic variation in selected muscles, tendons

36 and bones of the forelimbs in seventy-seven specimens belonging to seven anuran species of

37 different clades and of three age categories, and investigate the relative growth of the forelimb

38 musculoskeletal-tendinous structures throughout ontogeny. Ten muscles and nine tendons and

39 their respective large bones (humerus and radioulna) were removed intact, and their length was

40 measured and analysed through a multivariate approach of allometry. We obtained an allometry

41 coefficient, which indicates how the coefficient departures from isometry as well as allometric

42 trends. Our data suggest that along with the post-metamorphic ontogeny, muscles tend to

43 elongate proportionally to bone length, with a positive allometric trend. On the contrary, tendons

44 show a negative allometric growth trend. Only two species show different patterns: Rhinella

45 granulosa and Physalaemus biligonigerus, with an isometric and positive growth of muscles and

46 bones, and most tendons being isometric.

48 Keywords: muscles, bones, tendons, allometry, ontogeny, anuran

\section{Introduction}

50

51 The musculotendinous system is particularly active in the general limb movements. The tendons

52 unite and transmit the strength of the muscles to the bones, allowing movement dexterity, and the

53 distribution of the strength of the limbs to the digits (Kardong, 2002). The release of the elastic

54 energy of muscular aponeuroses and ligaments amplifies the power and reduces muscle work 
55 (Roberts, 2002; Biewener, 2003). The capacity for the differential jump between frog species is

56 related to the relative amount of musculature of the hindlimb and the use of the energy stored in

57 tendons and ligaments (Emerson, 1978). Further, tendons improve muscle performance for a

58 wide range of locomotor activities (Roberts, 2002).

59 During ontogeny, the characteristics of muscle architecture and connective tissue vary

60 according to the body length increase, and to the increase of daily activity functional demands.

61 Thus, many of the evolutionary and developmental transformations in structures related to the

62 locomotor function in anurans occur during larval stages and metamorphosis (Ročkova \& Roček,

63 2005; Púgener \& Maglia, 2009; Manzano et al., 2013; Fabrezi et al., 2014). Studies on anuran

64 ontogeny reveal that locomotor modes (walking, jumping, and swimming) are achieved before

65 the acquisition of the pelvis-sacral-urostil complex coordination, and the hindlimbs are acting as

66 a unit (Fabrezi et al., 2014). Although metamorphosis has been considered as the period in which

67 the most critical anatomical characteristics for adult locomotion are developed (for example,

68 those related to girdles and limbs; Fabrezi et al., 2014), it is known that tissue differentiation and

69 maturation of the structures involved in locomotion are completed during the juvenile stage

70 (Vera, Ponssa \& Abdala, 2015).

71 There are numerous studies on anuran ontogeny (Hanken \& Hall, 1984; De Sá, 1988; Hall \&

72 Larsen, 1988; Banbury \& Maglia, 2006; Handrigan \& Wassersug, 2007; Handrigan, Haas \&

73 Wassersug, 2007; Manzano et al., 2013; among many others); and on the relationship between

74 different ontogenetic trajectories and modes of life (Haas, 1999; Haas \& Richards, 1998;

75 Ročková \& Roček, 2005; Púgener \& Maglia, 2009; Manzano et al., 2013; Fabrezi et al., 2014;

76 Soliz \& Ponssa, 2016). However, considerably less attention has been given to the changes

77 occurring through juveniles and metamorphic stages (Ponssa \& Vera Candioti, 2012). Juveniles 
78 of most species must maneuver in the same environment and avoid the same predators as adults,

79 but they undergo ontogenetic changes that allow them to sprint and jump almost as fast and far

80 as adults. The allometric changes in juveniles include relatively longer limbs, muscular forces,

81 and relatively greater contractile speeds and higher muscular mechanical advantage (Carrier,

82 1995; Ponssa \& Vera Candioti, 2012).

83 Several researchers found that subtle structural differences in the proportion of hindlimbs

84 would facilitate functional diversity, allowing for wide-ranging exploitation of environments

85 (Duellman \& Trueb, 1994; Emerson, 1978; 1979; 1983; 1985; Emerson \& De Jongh, 1980;

86 Nauwelaerts, Ramsay \& Aerts, 2007). Ontogenetic processes have been considered responsible

87 of the morphological variability among species and could have a profound impact on the shape

88 of morphological structures (Thompson, 1942; Gould, 1977; Alberch, Gould \& Wake, 1979;

89 Calder, 1984; Schmidt-Nielsen, 1984; Emerson \& Bramble, 1993; Reilly, Wiley \& Meinhardt,

90 1997; Vukov et al., 2018). However, few studies have investigated the ontogenetic variation of

91 the musculotendinous system, which could be responsible for generating and transmitting force

92 to produce and control body movements. This active force is produced by the muscle fibers and

93 is transmitted to the bones through aponeuroses and tendons (Biewener, 1998; Böl, Leichsenring

$94 \&$ Siebert, 2017).

95 Here, we examined the ontogenetic variation in selected muscles, tendons, and bones of the

96 forelimbs in seven anuran species. Our main goal was to investigate the relative growth of the

97 forelimb musculoskeletal-tendinous structures throughout ontogeny. All the ontogenetic stages

98 considered here belong to the fully functional category (Muntz, 1976), implying that all tissues

99 and limb structures are integrated. We ask whether all those integrated tissues and limb

100 structures growth synchronically between them and along with body length, and hypothesize that 
101 our data will show a general allometric pattern of increased growth rate with larger body length.

102 The study of the effect of the ontogeny onto the longitudinal growth of the musculoskeletal-

103 tendinous structures of frogs represents a starting point to a more global analysis considering

104 other variables such as volume or cross-sectional areas.

105

\section{Materials and Methods}

107 The right forelimb of seventy-seven specimens belonging to six species encompassing different

108 clades of the anuran phylogeny (Duellman et al. 2016 and Pyron and Wiens, 2011) were

109 dissected (Table 1). Then, 10 muscles and 9 tendons, and their respective large bones (humerus

110 and radioulna) (Table 2) were removed intact, and their length was measured (Fig. 1). The

111 specimens were staged in three estimated categories according to Gosner (1960): metamorphic

11246 (2); juvenil (3); and adult (4). Dissections of the anatomical traits were performed between the

113 origin and insertion points under a binocular microscope (Nikon SMZ645), and were measured

114 in mm with digital callipers ( $\pm 0.01 \mathrm{~mm}$; Mitutoyo CD-15B, Mitutoyo Corp., Kure, Japan). When

115 referring to muscles, abbreviation "m." before muscle names was added; otherwise names refer

116 to tendons associated with those muscles (Table 1). The terminology used follows Prrikryl et al.

117 (2009), Abdala \& Diogo (2010), Diogo \& Ziermann (2014). Data of muscles measurements,

118 body length and number of individuals used per species are detailed as Table S1. All the

119 examined specimens are deposited in systematic collections, and listed in Table 1.

\section{Statistical Analysis}

122 To estimate the scaling of muscles and tendons throughout postnatal ontogeny of the forelimb we

123 performed a multivariate allometric tests based on the generalized allometric equation proposed 
124 by Jolicoeur (1963). We performed a principal component analysis (PCA) to obtain the 1st PC

125 eigenvector that expresses the scaling relationships among all variables with the latent size

126 regarded as a latent variable affecting all measured variables simultaneously (Giannini, Abdala

127 \& Flores, 2004; Giannini et al., 2010; Segura \& Prevosti, 2012). This eigenvector is extracted

128 from a variance-covariance matrix of $\log _{10}$-transformed variables and scaled to unity (Jolicoeur,

129 1963). The significance of multivariate allometry coefficients was tested using a resampling

130 strategy based on jackknife. Each specimen was removed from the sample at a time, generating $\mathrm{n}$

131 pseudovalues to calculate confidence intervals (CIs) for the original coefficients (Giannini et al.,

132 2004; Flores, Giannini \& Abdala., 2006). If the interval excluded an expected value of isometry,

133 the variable was considered positively or negatively allometric. For all multivariate coefficients

134 of allometry, the expected value of isometry, which depends only on the number of variables (p),

135 is calculated as $1 / \mathrm{p}^{0.5}(0.21)$ for our set of 22 variables). Trimming the largest and smallest $\mathrm{m}$

136 pseudovalues (with $\mathrm{m}=1$ ) for each variable may significantly decrease the standard deviations

137 calculated under jack-knife, and allow for more accurate allometric estimations (Manly, 1997;

138 Giannini et al., 2004). Here, untrimmed and trimmed calculations are reported, but the chosen

139 results are those with either lower average standard deviation, or lower bias (with the latter

140 defined as the difference between observed and jackknifed allometry coefficient; Giannini et al.,

141 2004).

142

\section{Results}

144 Individual values of the analysed morphological variables are shown in Table S1. Scaling 145 analyses describing ontogenetic growth in length and width of forelimb muscles and tendons in 146 seven frog species are shown in Table 3. Results of allometry multivariate analyses are given in 
147 Table 3. We report untrimmed $(\mathrm{m}=0)$ as well as trimmed $(\mathrm{m}=1)$ calculations of confidence

148 intervals, opting for the results with lower average standard deviation or bias, trimmed with CI

$14995 \%$ which combines the conservative safety of interval and estimated bias in these analyses .

\section{Musculoskeletal-tendinous allometry in Rhinella arenarum}

152 Trends obtained with untrimmed and trimmed values differed only in relation to five 153 variables: radioulna length (RUL), extensor carpi radialis tendon length (EcrT), humeralis 154 medialis tendon (HmedT) and $\mathrm{m}$. coracoradialis $(\mathrm{C})$. The greatest departure was observed in two 155 variables, m. flexor digitorum communis (Fdc) and m. flexor carpi ulnaris (Fcul) lengths (-0.213 156 and -0.208 , respectively). Two variables showed the smallest observed departure from isometry:

157 m. flexor carpi radialis (FcrT) and flexor carpi ulnaris tendon lengths (FculT) (0.061 and -0.068, 158 respectively). Based on this result, twelve variables significantly departed from isometry: 159 radioulna length (RUL), m. humeralis lateralis (Hlat), m. extensor digitorum (Edig), m. extensor 160 carpi ulnaris (Ecul), m. flexor digitorum communis (Fdc) and extensor carpi radialis tendon

161 length (EcrT), and body length (BL), all positively allometric. M. coracoradialis (C), humeralis 162 medialis tendon length (HmedT), flexor digitorum communis tendon length (FdcT), flexor carpi 163 ulnaris tendon length (FculT) and flexor carpi radialis tendon length (FcrT) were all negatively 164 allometric (Table S2).

165

\section{Musculoskeletal-tendinous allometry in Rhinella granulosa}

167 Trends obtained with untrimmed and trimmed values differed only in relation to five 168 variables: scapularis medialis tendon length (SMT), extensor carpi radialis tendon length (EcrT), $169 \mathrm{~m}$. coracoradialis (C), m. flexor carpi ulnaris (Fcul) and m. flexor carpi radialis (Fcr). The 
170 greatest departure was observed in two variables, m. extensor carpi ulnaris (Ecul) and extensor

171 carpi radialis tendon length (EcrT) $(0.320$ and 0.308 , respectively). The smallest departure

172 observed from isometry was found in scapularis medialis tendon length (SMT) and humeralis

173 lateralis tendon length (HlatTL) (0.108 and 0.082, respectively). Based on this result, six

174 variables significantly departed from isometry: humeralis lateralis tendon length (HlatT),

175 scapularis medialis tendon length (SMT), and m. coracoradialis (C; all negatively allometric);

176 and extensor carpi radialis tendon length (EcrT), m. flexor carpi ulnaris (Fcu) and $\mathrm{m}$. flexor carpi

177 radialis (Fcr; all positively allometric) (Table S3).

178

179 Musculoskeletal-tendinous allometry in Trachycephalus typhonius

180 Trends obtained with untrimmed and trimmed values differed only in relation to seven

181 variables: humerus length (HL), humeralis lateralis (Hlat), m. extensor carpi radialis (Ecr) and

182 tendon length (EcrT), m. extensor carpi ulnaris (Ecu) and tendon length (EcuT) and flexor

183 digitorum communis tendon length (FdcT) (Table 3). The greatest departure was observed in

184 three variables, m. scapularis medialis (SM) (0.272), extensor carpi radialis (Ecr) (0.259) and

185 extensor digitorum communis (Edc) (0.265) (Table 3). The smallest observed departure from

186 isometry was in extensor carpi ulnaris tendon length (EculT) and humeralis medialis tendon

187 length (HmedT) (0.07 and 0.107, respectively). Based on this result, ten variables significantly

188 departed from isometry: humeralis medialis tendon length (HmedT), extensor carpi radialis

189 tendon length (EcrT), extensor carpi ulnaris tendon length (EcuT) and flexor digitorum

190 communis tendon length (FdcT; all negatively allometric); and humerus length (HL), extensor

191 carpi radialis tendon length (EcrT), m. flexor carpi ulnaris (Fcu) and m. flexor carpi radialis (Fcr;

192 all positively allometric) (Table S4). 
194 Musculoskeletal-tendinous allometry in Physalaemus biligonigerus

195 Trends obtained with untrimmed and trimmed values differed only in relation to seven 196 variables: body length (BL), scapularis medialis (SM), humeralis medialis (Hlat), m. extensor

197 digitorum (Edig), m. extensor carpi radialis (Ecr), m. coracoradialis (C) and flexor carpi radialis

198 tendon length (FcrT) (Table 3). The greatest observed departure from isometry was observed 199 radioulna length (RUL) and coracoradialis tendon length (CT) (0.278 and 0.277, respectively).

200 The smallest departure was observed in three variables: extensor carpi ulnaris tendon length 201 (EcuT) (0.069), extensor carpi radialis tendon length (EcrT) (0.082) and humeralis medialis 202 tendon length (HmedT) (0.109). Based on this result, six variables significantly departed from 203 isometry: humeralis medialis tendon length (HmedT), extensor carpi radialis tendon length 204 (EcrT), extensor carpi ulnaris tendon length (EcuT; all negatively allometric), and humerus 205 length (HL), radioulna length (RUL), coracoradialis tendon length (CT; all positively allometric) 206 (Table S5).

\section{Musculoskeletal-tendinous allometry in Leptodactylus chaquensis}

209 Trends obtained with untrimmed and trimmed values differed only in relation to eight 210 variables: radioluna (RUL), m. scapularis medialis (SM), scapularis medialis tendon length 211 (SMT), humeralis medialis tendon length (HlatT), humeralis lateralis tendon length (HmedT), m. 212 coracoradialis (C), extensor carpi radialis tendon length (EcrT), and flexor carpi ulnaris tendon

213 length (FcuT) (Table 3e). The greatest observed departure from isometry was found in scapularis 214 medialis tendon length (0.29), m. extensor carpi ulnaris (0.295) and extensor carpi radialis 215 tendon length (0.315). The smallest departure was observed in four variables: humeralis medialis 
216 tendon length (0.09), flexor digitorum communis tendon length (0.02), flexor carpi ulnaris

217 tendon length (EcuT) (0.068) and flexor carpi radialis tendon length (EcrT) (0.061). Based on

218 this result, ten variables significantly departed from isometry: body length (BL), m. humeralis

219 lateralis (Hlat), humeralis medialis (Hmed), m. extensor digitorum (Edig), m. extensor carpi

220 ulnaris (Ecul), m. flexor digitorum communis (Fdc), m. flexor carpi radialis (Fcr; all positively

221 allometric); and flexor carpi radialis tendon length (FcrT), flexor carpi ulnaris tendon length

222 (FcuT), and flexor digitorum communis tendon length (FdT; all negatively allometric) (Table 223 S6).

224

225 Musculoskeletal-tendinous allometry in Pleurodema borellii

226 Trends obtained with untrimmed and trimmed values differ only in relation to five variables: 227 scapularis medialis tendon length (SMT), humeralis lateralis tendon length (HmedT), m. 228 coracoradialis $(\mathrm{C})$, flexor digitorum communis tendon length (FdcT) and $\mathrm{m}$. flexor carpi ulnaris 229 (Fcu) (Table 3). The greatest observed departure from isometry was observed in $\mathrm{m}$. humeralis 230 lateralis and $\mathrm{m}$. extensor digitorum (0.262 and 0.301 , respectively). The smallest departure was 231 observed in two variables: extensor carpi ulnaris tendon length (EcuT) and flexor digitorum 232 communis tendon length ( $\mathrm{FdcT})(0.05$ and 0.11 , respectively). Based on this result, five variables 233 significantly departed from isometry: radioulna length, $\mathrm{m}$. humeralis lateralis (Hlat), m. extensor 234 digitorum (Edig), m. extensor carpi ulnaris (Ecul; all positively allometric), and m. extensor 235 carpi ulnaris (Ecu; negatively allometric) (Table S7).

236

237 Discussion 
238 The main goal of the present study was to investigate the relative growth patterns of the forelimb

239 musculoskeletal-tendinous system in seven anuran species of three age categories. The general

240 allometric growth patterns inferred from our data indicate that along with the post-metamorphic

241 ontogeny of most studied anuran species, muscles tend to elongate proportionally to bone length,

242 with a positive allometric trend. On the contrary, tendons show a negative allometric growth

243 trend. Only two species show different trends: Rhinella granulosa and Physalaemus

244 biligonigerus, with an isometric and positive growth of muscles and bones, and most tendons

245 being isometric. This trend represents a synchronic growth of all structures, which is an

246 interesting pattern. Overall, the couple antagonist-agonist muscles do not present the same

247 tendency in the surveyed species. For example, the triceps generally grows with positive

248 allometry, and the coracoradialis (biceps) with negative allometry. On the contrary, in the

249 forearm of Rhinella and Physalaemus, agonist and antagonist muscles presented the same trend.

250 Taken together, these data might indicate that the differential growth of the musculoskeletal-

251 tendinous system might be related to the intrinsic nature of each tissue e.g., tendons increase

252 their lengths by apposition of collagen fibril segments in a complex and hierarchical process

253 (Zhang et al. 2005), meanwhile bone growth in length is mainly achieved through the action of

254 chondrocytes in the proliferative and hypertrophic zones (Rauch, 2005).

255 Manzano et al. (2013) stressed that the tendon is the last tissue to form during limb ontogeny

256 in anurans and that it needs a fully functional limb to reach complete maturity. Our data shows

257 that this delay in tendon appearance and growth occurs after reaching the fully functional stage,

258 as evidenced by its negative allometric growth. On the contrary, muscles and bones show the

259 same positive allometric trend. This coordinated growth trend contrasts with the previous

260 morphogenetic processes in which muscular differentiation seems to be extremely fast compared 
261 to the differentiation of the limb skeletal element (Manzano et al., 2013). Our results on postnatal

262 growth are concordant with the observations made by Huang et al. (2015) in mouse mutants

263 [Splotch delayed (Spd) mice (Vogan et al., 1993)]. These authors found that the first stage of

264 tendon development - in which muscles span the zeugopodium anchor to autopodium induced

265 tendons - might be better described through positive allometric muscle growth and a negative

266 allometric tendon elongation, and a subsequent reversal of this trend. Thus, the correct assembly

267 of the musculoskeletal-tendinous complex of a limb segment as unity is regulated by differential

268 growth, in a similar way to that proposed by Eilam (1997). In that study, a heterochronic process

269 was suggested as the critical factor to explain body morphology divergence in several rodent

270 taxa.

271 Heterochrony is a central process driving morphological diversity in mammals (Ravosa,

272 Meyers \& Glander, 1993; Maunz \& German, 1997; Richardson et al., 2009), which also seems to

273 modulate musculoskeletal-tendinous growth in anurans. The synchronic muscle-bone growth

274 combined with a negative allometric growth of tendon length results in a segment highly

275 occupied by muscle fibers. On the contrary, a positive allometric growth of the tendons length

276 combined with a synchronic and negative muscle-bone growth would result in a segment highly

277 occupied by tendons. This process could explain, for example, the differences between tendon

278 length of the forearm of a bat or a horse and that of a rat, and would provide a simple mechanism

279 to account for their highly specialized locomotor types.

280 When the relative growth of the arm and forearm structures of the analyzed anuran species are

281 compared, interesting trends emerge. In the forearm, there is a general trend of a positive bone

282 and muscle allometry, including extensors and flexors, and the already reported delayed tendon

283 growth. In the arm, there is a trend to a positive humerus and triceps allometry, combined with a 
284 negative coracoradialis allometry. Strikingly, the coracoradialis tendon presents isometric 285 growth. The described growth of the coracoradialis tendon, combined with negative allometric 286 muscle growth, indicates the presence of a forearm flexor layer with long tendons. Interestingly, 287 the pattern highlighted by Bobbert (2001) as an intriguing design aspect of the human 288 musculoskeletal system (distal muscle-tendon complexes spanning the distance between origin 289 and insertion, with long tendons and very short muscle fibers) was only recorded for the 290 coracoradialis. The longer tendon compared with the muscle length indicates a segment with less

291 force but faster reaction, which could compensate for the great force with slower reaction 292 indicated by the relative growth of the triceps.

293 In conclusion, our data indicate that the musculoskeletal-tendinous growth is different than 294 posed in our initial hypothesis: limb bones and muscles tend to develop synchronically, with 295 tendons exhibiting a delayed growth.

296

297 Data Availability

298 Supplementary File

299 Tables S1: The raw of muscles, bones and body measurements and a number of individuals used 300 per species.

301 Tables S2-S7: Summary of results of multivariate allometry.

302 Funding

303 This work was funded by the PIUNT 26/G625 and PIP CONICET 389 and PICT 2016-2772.

304 The funders had no role in study design, data collection and analysis, decision to publish, or 305 preparation of the manuscript.

\section{Acknowledgments}


308 We are very thankful to Marta Cánepa and Sonia Kretzschmar from Herpetology Collection of

309 the Fundación Miguel Lillo and Museo de Ciencias Naturales de la Universidad Nacional de

310 Salta for allowing access to herpetological collections. For helpful for improving the English

311 language, we thank to Sofía Nanni for providing suggestions that greatly improved the

312 manuscript.

\section{References}

314

315

Abdala V, Diogo R. 2010. Comparative anatomy, homologies and evolution of the pectoral and forelimb musculature of tetrapods with special attention to extant limbed amphibians and reptiles. Journal of Anatomy 217:536-573.

Alberch P, Gould SJ, Wake DB. 1979. Size and Shape in Ontogeny and Phylogeny. Paleobiology 5:296-317.

Banbury B, Maglia AM. 2006. Skeletal development of the mexican spadefoot, Spea multiplicata (Anura: Pelobatidae). Journal of Morphology 267:803-821.

Biewener AA. 1998. Muscle-tendon stresses and elastic energy storage during locomotion in the horse. Comparative Biochemistry Physiology Part B 120:73-87.

324 Biewener AA. 2003. Animal locomotion. Oxford: Oxford University Press.

Bobbert, MF. 2001. Dependence of human squat jump performance on the Series elastic compliance of the triceps surae: A simulation study. Journal of Experimental Biology 204:533-542.

Böl M, Leichsenring J, Siebert T. 2017. Effects of growth on muscle, tendon, and aponeurosis tissues in rabbit shank musculature. The Anatomical Records 300:1123-1136.

Calder WA III. 1984. Size, Function, and Life History. Harvard University Press.

Carrier DR. 1995. Ontogeny of jumping performance in the black-tailed jackrabbit (Lepus californicus). Zoology 98: 309-313.

333 Cei JM. 1950. Leptodactylus chaquensis $\mathrm{n}$. sp. y el valor sistemático real de la especie Linneana 334 Leptodactylus ocellatus en la Argentina. Acta Zoologica Lilloana 9:395-423.

335 Chaparro JC, Pramuk JB, Gluesenkamp AG. 2007. A new species of arboreal Rhinella (Anura: 336 
337 De Sá, R., 1988. Chondrocranium of ossification sequence of Hyla lanciformis. Journal of 338 Morphology 195:345-355.

339 Diogo R, Ziermann JM. 2014. Development of fore- and hindlimb muscles in frogs: 340 Morphogenesis, homeotic transformations, digit reduction, and the forelimb-hindlimb enigma.

341 Journal of Experimental Zoology Part B: Molecular and Developmental Evolution 322:86-05.

342 Duellman WE, Trueb L. 1994. Biology of Amphibians. The Johns Hopkins University Press.

343 Eilam D. 1997. Postnatal development of body architecture and gait in several rodent species. 344 Journal of Experimental Biology 200:339-1350.

345 Emerson S. 1978. Allometry and Jumping in frogs: helping the twain to meet. Evolution 32:551346564.

347 Emerson SB. 1979. The ilio-sacral articulation in frogs: form and function. Biological Journal of 348 the Linnean Society 11:153-168.

349 Emerson SB. 1982. Frog Postcranial morphology: identification of a functional complex. Copeia $350 \quad 3: 603-613$.

351 Emerson SB. 1983. Functional analysis of frog pectoral girdles. The epicoracoid cartilages. 352 Journal of Zoology 201:293-308.

353 Emerson SB. 1985. Heterochrony and frogs: the relationship of life history trait to 354 morphological form. American Naturalist 127:167-183.

Emerson SB, De Jongh HD. 1980. Muscle activity at the iliosacral articulation of frogs. Journal of Morphology 166:129-144.

Emerson SB, Bramble DM. 1993. Scaling, allometry, and skull design. In: Hanken J \& Hall BK, eds. The Skull, Vol. 3, Functional and Evolutionary Mechanisms. Chicago, IL: University of Chicago Press, 384-421.

360 Fabrezi M, Manzano A, Lobo F, Abdala V. 2014. Anuran locomotion: ontogeny and 361

362 morphological variation of a distinctive set of muscles. Evolutionary Biology 41:308-326

Flores DA, Giannini N, Abdala F. 2006. Comparative postnatal ontogeny of the skull in the australidelphian metatherian Dasyurus albopunctatus (Marsupialia: Dasyuromorpha: Dasyuridae). Journal of Morphology 267:426-440.

Giannini NP, Abdala F, Flores DA. 2004. Comparative postnatal ontogeny of the skull in Dromiciops gliroides (Marsupialia: Microbiotheriidae). American Museum Novitates 3460:117. 
368 Giannini NP, Segura V, Giannini MI, Flores D. 2010. A quantitative approach to the cranial

369

370

371

372

373

374

375

376

377

378

379

380

381

382

383

384

385

386

387

388

389

390

391

392

393

394

395

396

397 ontogeny of the puma. Mammalian Biology 75:547-554.

Gosner KL. 1960. A simplified table for staging anuran embryos and larvae with notes on identification. Herpetologica 16:183-190.

Gould SJ. 1977. Ontogeny and Phylogeny. Cambridge MA: Harvard Univ. Press.

Haas A, Richards JS. 1998. Correlations of cranial morphology, ecology, and evolution in australian suctorial tadpoles of the genera Litoria and Nyctimystes (Amphibia: Anura: Hylidae: Pelodryadinae). Journal of Morphology 238:109-141.

Haas A. 1999. Larval and metamorphic skeletal development in the fast-developing frog Pyxicephalus adspersus (Anura, Ranidae). Zoomorphology 119:23-35.

Hall JA, Larsen JH Jr. 1998. Postembryonic ontogeny of the spadefoot toad, Scaphiopus intermontanus (Anura: Pelobatidae): Skeletal morphology. Journal of Morphology 238:179244.

Handrigan GR, Wassersug RJ. 2007. The metamorphic fate of supernumerary caudal vertebrae in South Asian litter frogs (Anura: Megophryidae). Journal of Anatomy 211:271-279.

Handrigan GR, Haas A, Wassersug RJ. 2007. Bony-tailed tadpoles: the development of supernumerary caudal vertebrae in larval megophryids (Anura). Evolution \& Development 9:190-202.

Hanken J, Hall BK. 1984. Variation and timing of the cranial ossification sequence of the oriental fire-bellied toad, Bombina orientalis (Amphibia, Discoglossidae). Journal of Morphology 182:245-255.

Huang AH, Riordan TJ, Pryce B, Weibel JL, Watson SS, Long F, Tufa SF. 2015. Musculoskeletal integration at the wrist underlies the modular development of limb tendons. Development 142:2431-2441.

Jolicoeur P. 1963. The multivariate generalization of the allometry equation. Biometrics 19:497499.

Kardong KV. 2002. Vertebrates: Comparative Anatomy, Function, Evolution (3rd Ed.). New York: McGraw-Hill.

Lavilla EO, Langone JA, Padial JM, de Sá RO. 2010. The identity of the crackling, luminescent frog of Suriname (Rana typhonia Linnaeus, 1758) (Amphibia, Anura). Zootaxa 2671:17-30. 
398 Manzano A, Abdala V, Ponssa ML, Soliz M. 2013. Ontogeny and tissue differentiation of the pelvic girdle and hind limbs of anurans. Acta Zoologica Stockholm 94:420-436.

400

401

402

403

404

405

406

407

408

409

410

411

412

413

414

415

416

417

418

419

420

421

422

423

424

425

426

427

428

Maunz M, German RZ. 1997. Ontogeny and limb bone scaling in two New World marsupials, Monodelphis domestica and Didelphis virginiana. Journal of Morphology 231:117-130

Muntz L. 1976. Myogenesis in the trunk and leg during development of the tadpole of Xenopus laevis (Daudin 1802). Journal of Embryology and Experimental Morphology 33:757-77.

Nauwelaerts S, Ramsay J, Aerts P. 2007. Morphological correlates of aquatic and terrestrial locomotion in a semi-aquatic frog, Rana esculenta: No evidence for a design conflict. Journal of Anatomy 210:304-317.

Nieden F. 1923. Anura I. Subordo Aglossa und Phaneroglossa, Sectio 1. Arcifera. Das Tierreich 46, xxxii +584 .

Parker HW. 1927, A revision of the frogs of the genera Pseudopaludicola, Physalaemus, and Pleurodema. The Annals and Magazine of Natural History, Serie 9 20:458.

Pramuk JB, Robertson T, Sites JW Jr, Noonan BP. 2008. Around the world in 10 million years: biogeography of the nearly cosmopolitan true toads (Anura: Bufonidae). Global Ecology and Biogeography 17:72-83.

Ponssa ML, Vera Candioti MF. 2012. Patterns of skull development in anurans: size and shape relationship during postmetamorphic cranial ontogeny in five species of the Leptodactylus fuscus Group (Anura: Leptodactylidae). Zoomorphology 131:349-362.

Přikryl T, Aerts P, Havelková P, Herrel A, Roček Z. 2009. Pelvic and thigh musculature in frogs (Anura) and origin of anuran jumping locomotion. Journal of Anatomy 214:100-139

Púgener LA, Maglia AM. 2009. Developmental evolution of the anuran sacro-urostylic complex. South American Journal of Herpetology 4:193-20.

Ravosa MJ, Meyers DM, Glander KE. 1993. Relative growth of the limbs and trunk in sifakas: heterochronic, ecological, and functional considerations. American Journal of Physical Anthropology 92:499-520.

Reilly SM, Wiley EO, Meinhardt DJ. 1997. An integrative approach to heterochrony: the distinction between interspecific and intraspecific phenomena. Biological Journal of the Linnean Society 60:119-143.

Richardson MK, Gobes SM, van Leeuwen AC, Polman JA, Pieau C, Sánchez-Villagra MR. 2009. Heterochrony in limb evolution: developmental mechanisms and natural selection. 
429

430 Journal of Experimental Zoology Part B Molecular and Developmental Evolution 312:639664.

431 Roberts TJ. 2002. The integrated function of muscles and tendons during locomotion. 432 Comparative Biochemistry and Physiology. Part A, Molecular \& Integrative Physiology $433 \quad 33: 1087-99$.

434 Ročková H, Roček Z. 2005. Development of the pelvis and posterior part of the vertebral column 435 in the Anura. Journal of Anatomy 206:17-35.

436 Schmidt-Nielsen K. 1984. Scaling: Why is animal size so important? Cambridge: Cambridge 437 University Press.

438 Soliz MC, Ponssa ML. 2016. Development and Morphological Variation of the Axial and 439 Appendicular Skeleton in Hylidae (Lissamphibia, Anura). Journal of Morphology 277:786$440 \quad 813$.

441 Steindachner F. 1867. Reise der österreichischen Fregatte Novara um die Erde in den Jahren 1857, 1858, 1859 unter den Bafehlen des Commodore B. von Wüllerstorf-Urbair. Zologischer Theil. 1. Amphibien. Wien: K. K. Hof- und Staatsdruckerei.

444 Thompson DW. 1942. Growth and form. New York: Macmillan.

445 Vera MC, Ponssa ML, Abdala V. 2015. Further Data On Sesamoid Identity from Two Anuran $446 \quad$ Species. Anatomical Records 298:1376-1394.

447 Vogan KJ, Epstein DJ, Trasler DG, Gros P. 1993. The splotch delayed (Spd) mouse mutant 448 carries a point mutation within the paired box of the Pax-3 gene. Genomics 17:364-369.

449 Vukov TD, Kuručki M, Anđelković M, Kolarov NT. 2018. Post-metamorphic ontogenetic 450 changes in head size and shape of the pool frog (Pelophylax lessonae, Ranidae). Archives of 451 Biological Science 70:307-312.

452 


\section{Figure 1}

Figure 1. Muscles and tendons of the right forelimb of anuran species, and their respective large bones

A: dorsal view. B: ventral view. Light grey muscles and dark gray tendons. C: Coracoradialis. CT: Coracoradialis tendon. Ecr: Extensor carpi radialis. EcrT: Extensor carpi radialis tendon. Ecul: Extensor carpi ulnaris. EculT: Extensor carpi ulnaris tendon. EDig: Extensor digitorum. Fcr: Flexor carpi radialis. FcrT: Flexor carpi radialis tendon. Fcul: Flexor carpi ulnaris. FculT: Flexor carpi ulnaris tendón. Fdc: Flexor digitorum comunis. FdcT: Flexor digitorum comunis tendon. H: humerus. Hlat: Triceps humeralis lateralis. HlatT: Triceps humeralis lateralis tendon. Hmed: Triceps humeralis medialis. HmedT: Triceps humeralis medialis tendon. RU: radioulna. SMT: Triceps scapularis medialis. SMTT: Triceps scapularis medialis tendon. Scale bars: $5 \mathrm{~mm}$ 
A

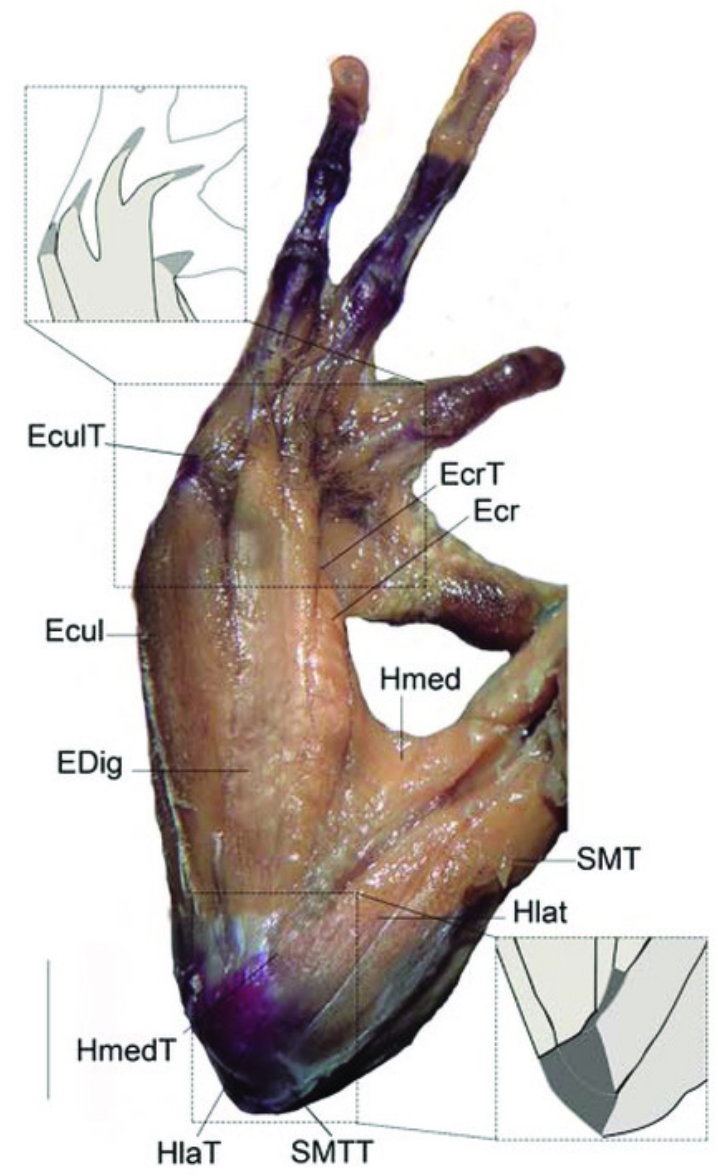

B

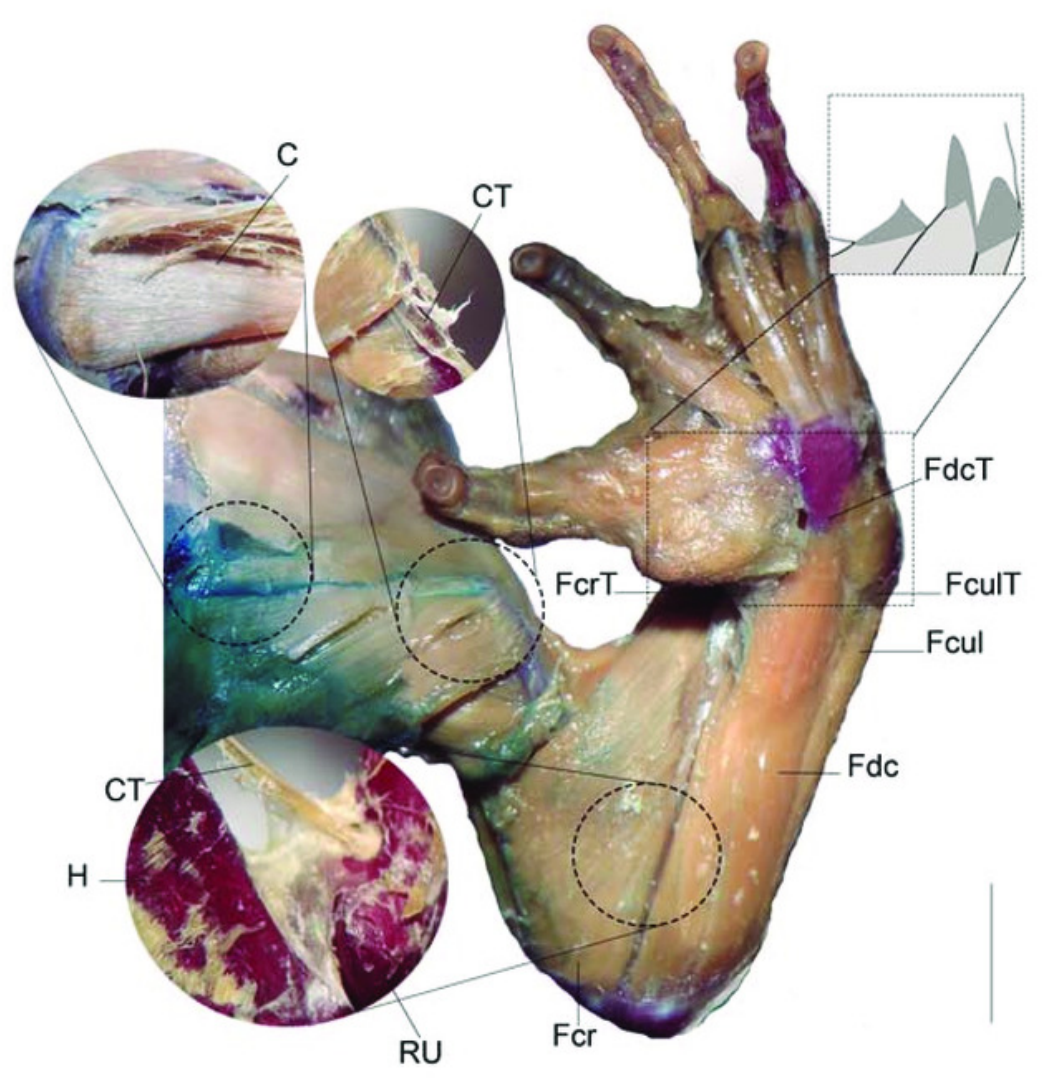




\section{Table $\mathbf{1}$ (on next page)}

List of anuran specimens examined. Acronyms for Argentinian institutions where specimens are deposited and personal catalogs: MCN: Museo de Ciencias Naturales de Salta, FML: Fundación Miguel Lillo. MS: field number of Mónica Soliz to be deposited at FML. 


\begin{tabular}{lcl}
\hline \multicolumn{1}{c}{ Species } & N & \multicolumn{1}{c}{ Specimen number } \\
\hline Rhinella arenarum & 18 & MCN594, MCN849, MCN858, MCN579, MCN776 \\
Rhinella granulosa & 9 & MCN775, MCN994, MCN779, MS0130, MS0131, MS0132 \\
Pleurodema borellii & 29 & MCN707, MCN592, MCN844, MS0133, MS0134, MS0135 \\
Physalaemus biligonigerus & 11 & MCN731, MS0137, MS136 \\
Leptodactylus chaquensis & 12 & MCN327, MCN166, MCN327, MCN583, MCN789 \\
Trachycephalus typhonius & 11 & FML29062, FML29133, FML29167, FML29168, MS0129 \\
\hline
\end{tabular}




\section{Table 2 (on next page)}

List of abbreviations of forelimb muscle, tendons, bones and body length of de measured specimens 


\begin{tabular}{|c|c|c|c|c|}
\hline Muscles & Abbreviations & Tendon & Abbreviations & Group \\
\hline \multicolumn{5}{|l|}{ Extensor } \\
\hline $\begin{array}{l}\text { Triceps scapularis } \\
\text { medialis }\end{array}$ & SMT & $\mathrm{x}$ & SMTT & Triceps \\
\hline Triceps humeralis lateralis & Hlat & $\mathrm{x}$ & HlatT & Triceps \\
\hline Triceps humeralis medialis & Hmed & $\mathrm{x}$ & HmedT & Triceps \\
\hline Extensor carpi radialis & Ecr & $\mathrm{x}$ & EcrT & Extensor of the forearm \\
\hline Extensor carpi ulnaris & Ecul & $\mathrm{x}$ & EculT & Extensor of the forearm \\
\hline Extensor digitorum & EDig & & & Extensor of the forearm \\
\hline \multicolumn{5}{|l|}{ Flexor } \\
\hline Coracoradialis & $\mathrm{C}$ & $\mathrm{x}$ & CT & Flexor of the arm \\
\hline Flexor carpi radialis & Fcr & $\mathrm{x}$ & FcrT & Flexor of the forearm \\
\hline Flexor carpi ulnaris & Fcul & $\mathrm{x}$ & FculT & Flexor of the forearm \\
\hline Flexor digitorum comunis & Fdc & $\mathrm{x}$ & FdcT & Flexor of the forearm \\
\hline \multicolumn{5}{|l|}{ Bones } \\
\hline Humerus length & $\mathrm{HL}$ & & & Arm \\
\hline Radioulna length & RUL & & & Forearm \\
\hline Body length & $\mathrm{BL}$ & & & \\
\hline
\end{tabular}

3 


\section{Table 3(on next page)}

Summary of allometric trends in the seven species of anuran for 20 variables investigated. The used symbols are: "+" (accelerated with respect to overall size or positive allometric), "-" (respect to overall size or negative allometric), "=" (isometric 


\begin{tabular}{|c|c|c|c|c|c|c|c|c|c|c|c|c|}
\hline \multirow{2}{*}{$\begin{array}{l}\text { Species } \\
\text { Variables }\end{array}$} & \multicolumn{2}{|c|}{ Rhinella arenarum } & \multicolumn{2}{|c|}{ Rhinella granulosa } & \multicolumn{2}{|c|}{$\begin{array}{c}\text { Trachycephalus } \\
\text { typhonius }\end{array}$} & \multicolumn{2}{|c|}{$\begin{array}{l}\text { Physalaemus } \\
\text { biligonigerus }\end{array}$} & \multicolumn{2}{|c|}{$\begin{array}{c}\text { Leptodactylus } \\
\text { chaquensis }\end{array}$} & \multicolumn{2}{|c|}{$\begin{array}{l}\text { Pleurodema } \\
\text { borelli }\end{array}$} \\
\hline & $\begin{array}{l}\text { Untrimme } \\
\text { d }\end{array}$ & $\begin{array}{l}\text { Trimme } \\
\text { d }\end{array}$ & $\begin{array}{l}\text { Untrimme } \\
\text { d }\end{array}$ & Trimmed & Untrimmed & $\begin{array}{l}\text { Trimm } \\
\text { ed }\end{array}$ & $\begin{array}{l}\text { Untrimme } \\
\text { d }\end{array}$ & $\begin{array}{l}\text { Trimm } \\
\text { ed }\end{array}$ & $\begin{array}{l}\text { Untrimme } \\
\text { d }\end{array}$ & $\begin{array}{l}\text { Trimm } \\
\text { ed }\end{array}$ & $\begin{array}{l}\text { Untrimm } \\
\text { ed }\end{array}$ & $\begin{array}{l}\text { Trimm } \\
\text { ed }\end{array}$ \\
\hline$B L$ & + & + & $=$ & $=$ & $=$ & $=$ & + & $=$ & + & + & $=$ & $=$ \\
\hline HL & $=$ & $=$ & $=$ & $=$ & + & $=$ & + & + & $=$ & $=$ & $=$ & $=$ \\
\hline SM & $=$ & + & $=$ & $=$ & + & + & + & $=$ & + & $=$ & $=$ & $=$ \\
\hline SMTL & $=$ & + & - & $=$ & $=$ & $=$ & $=$ & $=$ & + & $=$ & - & $=$ \\
\hline Hlat & + & + & $=$ & $=$ & + & $=$ & $=$ & $=$ & + & + & + & + \\
\hline HlatTL & $=$ & - & - & - & $=$ & $=$ & $=$ & $=$ & - & $=$ & - & $=$ \\
\hline Hmed & + & + & $=$ & $=$ & $=$ & $=$ & - & $=$ & + & + & $=$ & $=$ \\
\hline HmedTL & $=$ & - & $=$ & $=$ & - & - & - & - & - & $=$ & $=$ & $=$ \\
\hline Edig & + & + & $=$ & $=$ & + & + & + & $=$ & + & + & + & + \\
\hline Ecul & + & + & $=$ & $=$ & + & $=$ & $=$ & $=$ & + & + & + & + \\
\hline EculT & $=$ & $=$ & $=$ & $=$ & - & $=$ & - & - & $=$ & $=$ & - & - \\
\hline Ecr & $=$ & $=$ & $=$ & $=$ & + & $=$ & - & $=$ & $=$ & $=$ & $=$ & $=$ \\
\hline EcrT & $=$ & + & + & $=$ & - & $=$ & - & - & + & $=$ & $=$ & $=$ \\
\hline C & $=$ & - & - & $=$ & $=$ & $=$ & + & $=$ & - & $=$ & - & $=$ \\
\hline CTL & $=$ & $=$ & $=$ & $=$ & $=$ & $=$ & + & + & $=$ & $=$ & $=$ & $=$ \\
\hline Fdc & + & + & $=$ & $=$ & $=$ & $=$ & $=$ & $=$ & + & + & $=$ & $=$ \\
\hline FdcT & - & - & $=$ & $=$ & - & $=$ & $=$ & $=$ & - & - & - & $=$ \\
\hline Fcul & $=$ & + & + & $=$ & $=$ & $=$ & $=$ & $=$ & + & $=$ & + & $=$ \\
\hline FculT & - & - & $=$ & $=$ & $=$ & $=$ & $=$ & $=$ & - & - & $=$ & $=$ \\
\hline Fcr & + & + & + & $=$ & $=$ & $=$ & $=$ & $=$ & + & + & $=$ & $=$ \\
\hline
\end{tabular}

